\title{
Effectiveness and safety of intravenous application of dexmedetomidine for cesarean section under general anesthesia: a meta-analysis of randomized trials
}

This article was published in the following Dove Medical Press journal:

Drug Design, Development and Therapy

\author{
Li Aol,* \\ Jinlin $\mathrm{Shi}^{2}{ }^{2 * *}$ \\ Yaowu Bai' \\ Yujuan Zheng' \\ Jianhui Gan² \\ 'Department of Anesthesiology, \\ Tangshan Maternity and Child \\ Healthcare Hospital, Tangshan \\ 063000, Hebei, China; ${ }^{2}$ Department \\ of Anesthesiology, Tangshan People's \\ Hospital, North China University \\ of Science and Technology, Tangshan \\ 063000, Hebei, China \\ *These authors contributed equally \\ to this work
}

\begin{abstract}
Objective: The meta-analysis was conducted to assess the effectiveness and safety of intravenous administration of dexmedetomidine for cesarean section under general anesthesia, as well as neonatal outcomes.
\end{abstract}

Materials and methods: We searched PubMed, Embase, Cochrane Central Register of Controlled Trials and the China National Knowledge Infrastructure database for relevant randomized controlled trials (RCTs) about the application of intravenous dexmedetomidine under general anesthesia for cesarean section. RevMan 5.3 was used to conduct the meta-analysis of the outcomes of interest.

Results: Eight RCTs involved 376 participants were included in this study. The meta-analysis showed that the mean blood pressure at the time of intubation (weighted mean difference [WMD]: $-15.67,95 \% \mathrm{CI}:-21.21,-10.13, P<0.00001$ ), skin incision (WMD: $-12.83,95 \%$ CI $-20.53,-5.14, P=0.001$ ), and delivery (WMD: $-11.65,95 \%$ CI $-17.18,-6.13, P<0.0001$ ) in dexmedetomidine group were significantly lower than that in the control group. The heart rate (HR) at the time of intubation (WMD: $-31.41,95 \% \mathrm{CI}-35.01,-27.81, P<0.00001$ ), skin incision (WMD: $-22.32,95 \% \mathrm{CI}-34.55,-10.10, P=0.0003$ ), and delivery (WMD: -19.07 , $95 \%$ CI $-22.09,-16.04, P<0.00001)$ were also lower than that in control group. For neonatal parameters, no differences existed in umbilical blood gases at delivery, and Apgar scores at 1 minute (WMD: $-0.12,95 \% \mathrm{CI}-0.37,0.12, P=0.33$ ) and 5 minutes (WMD: $-0.17,95 \% \mathrm{CI}-0.13$, $0.46, P=0.27$ ) among two groups.

Conclusion: Intravenous administration of dexmedetomidine could efficiently attenuate the maternal cardiovascular response during cesarean section, without affecting Apgar score of the neonate. Keywords: dexmedetomidine, general anesthesia, cesarean section, cardiovascular response, meta-analysis, randomized controlled trial

\section{Introduction}

The implementation of obstetric anesthesia has become increasingly challenging as we are facing more and more complex and critical patients in clinical practice. Under these circumstances, effective management of anesthesia is of great importance to ensure the safety of the mother and fetus during a cesarean section. Although neuraxial anesthesia has been widely used for cesarean section, it was not feasible for patients with certain contraindications. Besides, severe cardiopulmonary complications, incomplete nerve block, and emergencies during cesarean section could further result in difficulties of neuraxial anesthesia strategies. ${ }^{1}$ For those cases with serious comorbidities,
Department of Anesthesiology, Tangshan People's Hospital and Tangshan Cancer Hospital, North China University of Science and Technology, No 65 Shengli Road, Tangshan 063000, Hebei, China

$\mathrm{Tel}+86$ I33 6320 I508

Email ganjianhui666@।63.com 
general anesthesia has become the first choice for cesarean delivery in terms of certain circumstance. Various anesthetics have been used during cesarean section under general anesthesia, some of which have the potential to cause neonatal respiratory depression. ${ }^{2-4}$ Tracheal intubation and surgical stimulation could cause significant hemodynamic changes. Opioids were usually used to attenuate the hemodynamic response, but could result in certain critical adverse reactions, such as respiratory depression of the neonate which limited the application of the anesthetics before delivery. ${ }^{3}$

As a highly selective alpha-2-adrenoceptor agonist, dexmedetomidine was widely used for sedation, anxiolysis, and analgesia effects during general or local anesthesia. 5,6 It reduced the requirement of anesthetics and cardiovascular responses associated with invasive anesthesia procedure, decreased surgical stress, characterized by little effect on respiration. ${ }^{7}$ Recently, intravenous application of dexmetetomidine has been used in addition to spinal anesthesia ${ }^{8,9}$ and as an adjuvant for cesarean section. ${ }^{10-14}$

Clinical researchers have already investigated the efficacy and safety of intravenous dexmedetomidine for cesarean section under spinal anesthesia, ${ }^{8,15}$ but the application of dexmedetomidine for cesarean section under general anesthesia is still controversial. Therefore, we conducted a meta-analysis to investigate the efficacy of intravenous applications of dexmedetomidine on perioperative maternal hemodynamics and neonatal outcome during cesarean section under general anesthesia.

\section{Materials and methods Literature search}

Two investigators independently searched databases, including PubMed, Embase, Cochrane Central Register of Controlled Trials and China National Knowledge Infrastructure through the month of November 2018, without language limitation. The search strategy included a combination of free text words and medical subject headings terms as follows: "Dexmedetomidine", "Adrenergic $\alpha$-Agonists", "cesarean section", "C-section", "cesarean delivery", "abdominal delivery", "general anesthesia" and "Randomized controlled trial". We also obtained additional articles by reviewing the references of relevant articles to prevent the missing randomized controlled trials (RCTs). Articles were considered for further analysis which reported the dexmedetomidine used for the induction of general anesthesia for cesarean section.

\section{Inclusion criteria}

Eligible criteria: 1) original and independent RCTs, 2) involved participants $\geq 18$ years; 3 ) American Society of
Anesthesiologists (ASA) physical status I or II, 4) intravenous dexmedetomidine was used for cesarean section under general anesthesia, and 5) outcomes included maternal mean arterial pressure (MAP) and heart rate (HR), umbilical blood gas parameters and Apgar scores.

\section{Data extraction and quality assessment}

Two reviewers independently assessed the trails complied with the eligibility criteria, extracted data and recorded the trial characteristics, while another reviewer checked the extracted data. The following information was collected: the first author, publication year, sample size, ASA physical status, details of dexmedetomidine administration, and interest of outcomes and anesthetic drug administration in each period of anesthesia (Table 1).

The risk of bias of individual studies was assessed independently by using the Cochrane risk-of-bias tool. ${ }^{16}$ The following aspects were assessed for each included study: 1) adequate sequence generation, 2) allocation concealment, 3) blinding, 4) incomplete outcome data, 5) selective reporting, and 6) other potential sources of bias. If there was any divergence, disagreements were resolved by the corresponding author when the two authors failed to reach an agreement.

\section{Data analysis}

Review manager version 5.3 statistical software ${ }^{17}$ (The Cochrane Collaboration, The Nordic Cochrane Center, Copenhagen, Denmark) was used to pool and analyze the studies. Risk ratios and 95\% CI were calculated for dichotomous data, and weighted mean differences (WMD) for continuous data. The heterogeneity $\chi^{2}$ was calculated as the $I^{2}$ for the variation due to heterogeneity, and $I^{2}$ values $>50 \%$ were considered significant. Data were analyzed with a fixed effects model which were not significantly homogeneous $\left(I^{2}<50 \%\right)$, otherwise, a random-effect model was followed. ${ }^{16}$ Estimated means and SDs were derived from the sample sizes, medians, range, and the IQRs using the formulas described by Luo et $\mathrm{al}^{18}$ and Wan et $\mathrm{al}^{19}$ (Figure 1).

\section{Results Study selection}

Initially, 45 articles were included in accordance with our search strategy. A total of 31 publications were excluded at this stage by reading titles and abstracts and analyzing and evaluating them for exclusion criteria. The remaining 14, potentially relevant, publications were selected for further analyses. Finally, only $8 \mathrm{RCTs}^{10-13,20-23}$ involving 
Table I Details of included studies

\begin{tabular}{|c|c|c|c|c|c|c|}
\hline Author & Country & $\begin{array}{l}\text { Age } \\
\text { (years) }\end{array}$ & $\begin{array}{l}\text { Sample } \\
\text { size }\end{array}$ & $\begin{array}{l}\text { Details of the } \\
\text { interventions }\end{array}$ & $\begin{array}{l}\text { Target } \\
\text { outcomes }\end{array}$ & $\begin{array}{l}\text { Anesthetics used during } \\
\text { surgery }\end{array}$ \\
\hline $\begin{array}{l}\text { El-Tahan } \\
\text { et al, } 2012^{10}\end{array}$ & Saudi Arabia & $18-35$ & $17 / 17$ & $\begin{array}{l}\text { Dex group: } 0.1 \mathrm{~mL} / \mathrm{kg} / \mathrm{h} \\
\text { of solution containing } \\
\text { dexmedetomidine } 4 \mu \mathrm{g} / \mathrm{mL} \\
\text { continuously IV; control } \\
\text { group: } 0.9 \% \text { normal saline } \\
0.1 \mathrm{~mL} / \mathrm{kg} / \mathrm{h} \mathrm{IV}\end{array}$ & 4,5 & $\begin{array}{l}\text { Induction: propofol, } \\
\text { suxamethonium; maintenance: } \\
\text { sevoflurane, NO, rocuronium, } \\
\text { fentanyl; emergence: diclofenac, } \\
\text { paracetamol. }\end{array}$ \\
\hline $\begin{array}{l}\text { Eskandr } \\
\text { et al, } 2018^{\prime \prime}\end{array}$ & Egypt & $18-40$ & $20 / 20$ & $\begin{array}{l}\text { Dex group: dexmedetomidine } \\
\text { bolus I } \mu \mathrm{g} / \mathrm{kg}, 0.4 \mu \mathrm{g} / \mathrm{kg} / \mathrm{h} \\
\text { continuously IV; control } \\
\text { group: equivalent volume of } \\
0.9 \% \text { normal saline IV }\end{array}$ & 5 & $\begin{array}{l}\text { Induction: propofol, rocuronium; } \\
\text { maintenance: sevoflurane, fentanyl; } \\
\text { emergence: morphine. }\end{array}$ \\
\hline $\begin{array}{l}\text { Kart and } \\
\text { Hanci, } 2018^{12}\end{array}$ & Turkey & $18-42$ & $30 / 30$ & $\begin{array}{l}\text { Dex group: dexmedetomidine } \\
\text { I } \mu g / \mathrm{kg} \text {; control group: } \\
\text { equivalent volume of } 0.9 \% \\
\text { normal saline IV }\end{array}$ & I, 2, 3 & $\begin{array}{l}\text { Induction: propofol, rocuronium; } \\
\text { maintenance: sevoflurane, fentanyl; } \\
\text { emergence: levobupivacaine; }\end{array}$ \\
\hline $\begin{array}{l}\text { Yu et al, } \\
2015^{13}\end{array}$ & China & $22-37$ & $17 / 18$ & $\begin{array}{l}\text { Dex group: dexmedetomidine } \\
\text { bolus } 0.6 \mu \mathrm{g} / \mathrm{kg}, 0.4 \mu \mathrm{g} / \mathrm{kg} / \mathrm{h} \\
\text { continuously IV; control } \\
\text { group: equivalent volume of } \\
0.9 \% \text { normal saline IV }\end{array}$ & $2,3,4,5$ & $\begin{array}{l}\text { Induction: propofol, remifentanil, } \\
\text { cisatracurium; maintenance: } \\
\text { sevoflurane, propofol, remifentanil, } \\
\text { fentanyl, midazolam; emergence: } \\
\text { not mentioned. }\end{array}$ \\
\hline $\begin{array}{l}\text { Song et al, } \\
2017^{20}\end{array}$ & China & $21-35$ & $30 / 30$ & $\begin{array}{l}\text { Dex group: dexmedetomidine } \\
0.8 \mu \mathrm{g} / \mathrm{kg} / \mathrm{h} \text { continuously IV; } \\
\text { control group: } 0.9 \% \\
\text { normal saline } 0.8 \mu \mathrm{g} / \mathrm{kg} / \mathrm{h} \\
\text { continuously IV }\end{array}$ & I, 2, 3 & $\begin{array}{l}\text { Induction: propofol, rocuronium; } \\
\text { maintenance: propofol, } \\
\text { remifentanil; emergence: not } \\
\text { mentioned. }\end{array}$ \\
\hline $\begin{array}{l}\text { Deng and } \\
\mathrm{Wu}, 2015^{21}\end{array}$ & China & $21-35$ & $20 / 20$ & $\begin{array}{l}\text { Dex group: dexmedetomidine } \\
0.8 \mu \mathrm{g} / \mathrm{kg} / \mathrm{h} \text { continuously IV; } \\
\text { control group: } 0.9 \% \\
\text { normal saline } 0.8 \mu \mathrm{g} / \mathrm{kg} / \mathrm{h} \\
\text { continuously IV }\end{array}$ & $I, 2,3,4$ & $\begin{array}{l}\text { Induction: propofol, rocuronium; } \\
\text { maintenance: sevoflurane, } \\
\text { propofol, remifentanil; emergence: } \\
\text { not mentioned. }\end{array}$ \\
\hline $\begin{array}{l}\text { Wu et al, } \\
2015^{22}\end{array}$ & China & $22-37$ & $17 / 17$ & $\begin{array}{l}\text { Dex group: dexmedetomidine } \\
\text { bolus } 0.6 \mu \mathrm{g} / \mathrm{kg}, 0.4 \mu \mathrm{g} / \mathrm{kg} / \mathrm{h} \\
\text { continuously IV; control } \\
\text { group: equivalent volume of } \\
0.9 \% \text { normal saline IV }\end{array}$ & I, $3,4,5$ & $\begin{array}{l}\text { Induction: propofol, remifentanil, } \\
\text { cisatracurium; maintenance: } \\
\text { propofol, remifentanil, atracurium, } \\
\text { fentanyl, midazolam; emergence: } \\
\text { not mentioned. }\end{array}$ \\
\hline $\begin{array}{l}\text { Shi et al, } \\
2018^{23}\end{array}$ & China & $\begin{array}{l}\text { Not } \\
\text { available }\end{array}$ & $32 / 41$ & $\begin{array}{l}\text { Dex group: dexmedetomidine } \\
\text { bolus } 0.4 \mu \mathrm{g} / \mathrm{kg}, 0.4 \mu \mathrm{g} / \mathrm{kg} / \mathrm{h} \\
\text { continuously IV; control } \\
\text { group: equivalent volume of } \\
0.9 \% \text { normal saline IV }\end{array}$ & 4,5 & $\begin{array}{l}\text { Induction: propofol, cisatracurium; } \\
\text { maintenance: propofol, fentanyl, } \\
\text { midazolam; emergence: not } \\
\text { mentioned. }\end{array}$ \\
\hline
\end{tabular}

Notes: I) MAP and heart rate (HR) at the time of intubation; 2) MAP and $\mathrm{HR}$ at the time of skin incision; 3) MAP and $\mathrm{HR}$ at the time of delivery; 4) $\mathrm{PH}$, $\mathrm{PO}$ and $\mathrm{pCO}{ }_{2}$ of umbilical blood gas; 5) Apgar scores at I minute and 5 minutes after delivery.

Abbreviations: Dex, dexmedetomidine; MAP, mean arterial pressure; NO, nitrous oxide.

376 participants were included. Details of the trials are shown in Figure 2.

\section{Study characteristics}

Published RCTs were considered for inclusion when they involved intravenous application of dexmedetomidine for cesarean section under general anesthesia. All included studies investigated the effectiveness and safety of intravenous application of dexmedetomidine as an adjuvant for cesarean section, compared with controlled interventions (IV normal saline or other placebos). At least one of the following outcomes was reported: maternal MAP and HRs, venous umbilical blood gas $\left(\mathrm{pH}, \mathrm{pO}_{2}, \mathrm{pCO}_{2}\right.$, etc.) and Apgar scores.

\section{Risk of bias within studies}

Four trials ${ }^{10,13,20,22}$ were adequate for sequence generation, and unclear sequence generation was reported in one trial. ${ }^{23}$ Only one study ${ }^{23}$ had high risk for allocation concealment. Blinding of participants was unclear in two trials, ${ }^{22,23}$ and two trials ${ }^{12,20}$ had high risk of bias. Adequate blinding of outcome assessment was found in four trials, ${ }^{10,13,21,22}$ while it 
The sample mean and standard deviation were estimated by following formulas, when the median, the minimum, the maximum, and the sample size were given in a study.

$$
\begin{aligned}
& \bar{X} \approx\left(\frac{4}{4+n^{0.75}}\right) \frac{a+b}{2}+\left(\frac{n^{0.75}}{4+n^{0.75}}\right) m \\
& \mathrm{SD} \approx \frac{b-a}{2 \Phi^{-1}\left(\frac{n-0.375}{n+0.25}\right)}
\end{aligned}
$$

The sample mean and standard deviation were estimated by following formulas, when the median, the first quartiles, the third quartiles, and the sample size were given in a study.

$$
\begin{aligned}
& \bar{X} \approx\left(0.7+\frac{0.39}{n}\right) \frac{q_{1}+q_{3}}{2}+\left(0.3-\frac{0.39}{n}\right) m \\
& \mathrm{SD} \approx \frac{q_{3}-q_{1}}{2 \Phi^{-1}\left(\frac{0.75 n-0.125}{n+0.25}\right)}
\end{aligned}
$$

The summary statistics were defined as follows:

$$
\begin{aligned}
& a=\text { the minimum value } \\
& q_{1}=\text { the first quartile, } \\
& m=\text { the median, } \\
& q_{3}=\text { the third quartile, } \\
& b=\text { the maximum value } \\
& n=\text { the sample size. }
\end{aligned}
$$

Figure I The relevant calculation formulas of SD and mean.

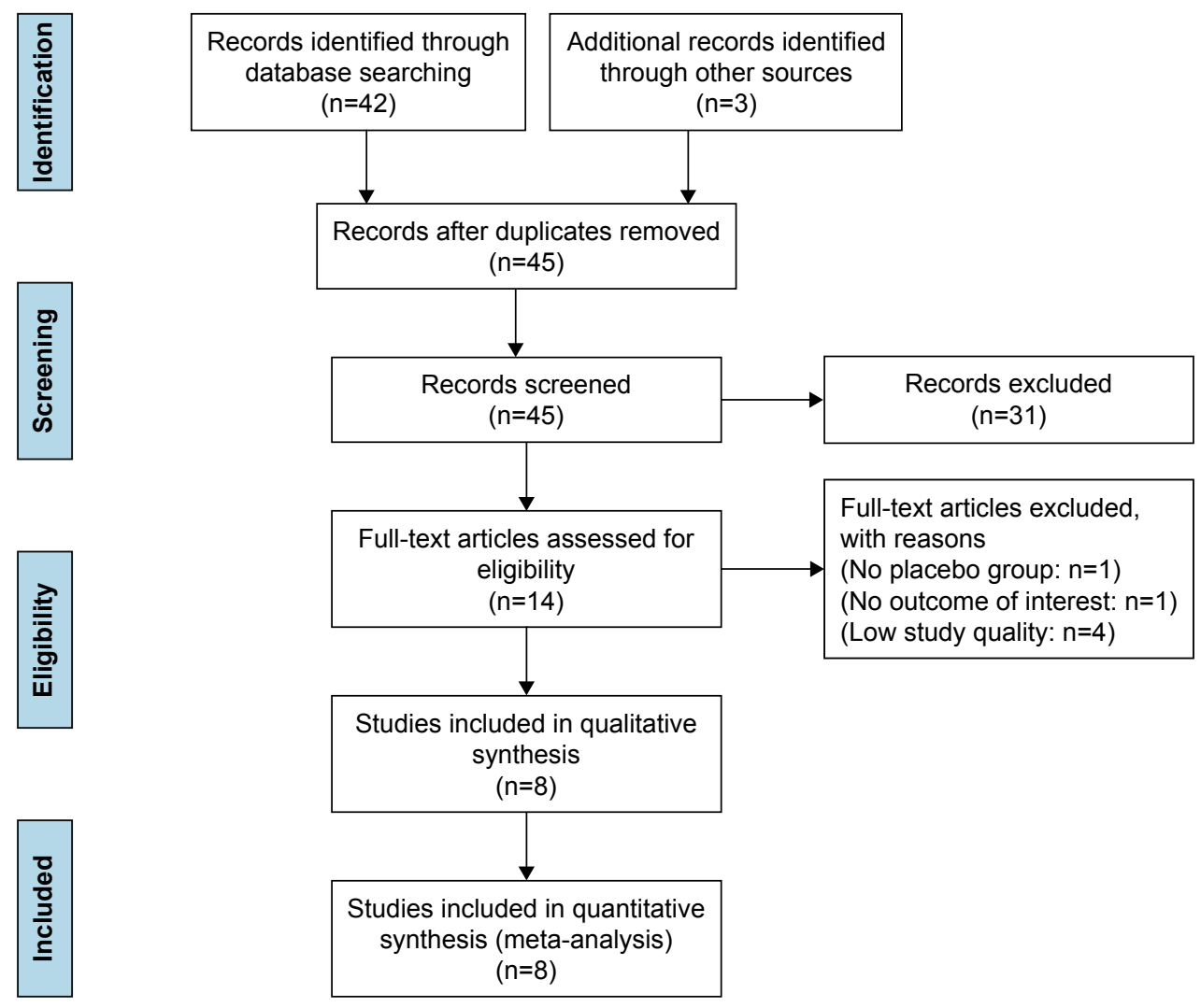

Figure 2 Flowchart of the study selection process. 
was inadequate in two trials. ${ }^{12,23}$ Seven trials ${ }^{10-12,20-23}$ had low risk of incomplete outcome data, and there was also a low risk of reporting bias in seven trials..$^{11-13,20-23}$ (Figure 3).

\section{Maternal outcome}

All researchers measured MAP and HR at the different time points during perioperative period. Four trials ${ }^{12,20-22}$ measured the MAP and HR at the time of intubation. Statistical heterogeneity was found in $\operatorname{MAP}\left(I^{2}=57 \%\right)$, but not in HR $\left(I^{2}=0 \%\right)$. Therefore, the random effects model and fixed effects model were performed for the meta-analysis. The results suggested that the MAP (WMD: $-15.67,95 \%$ CI $-21.21,-10.13, P<0.00001)$ and HR (WMD: -31.41 , $95 \%$ CI $-35.01,-27.81, P<0.00001)$ were significantly lower in the dexmedetomidine group than that in control group at the time of intubation. Four studies ${ }^{12,13,20,21}$ recorded the MAP and $\mathrm{HR}$ at the time of skin incision.

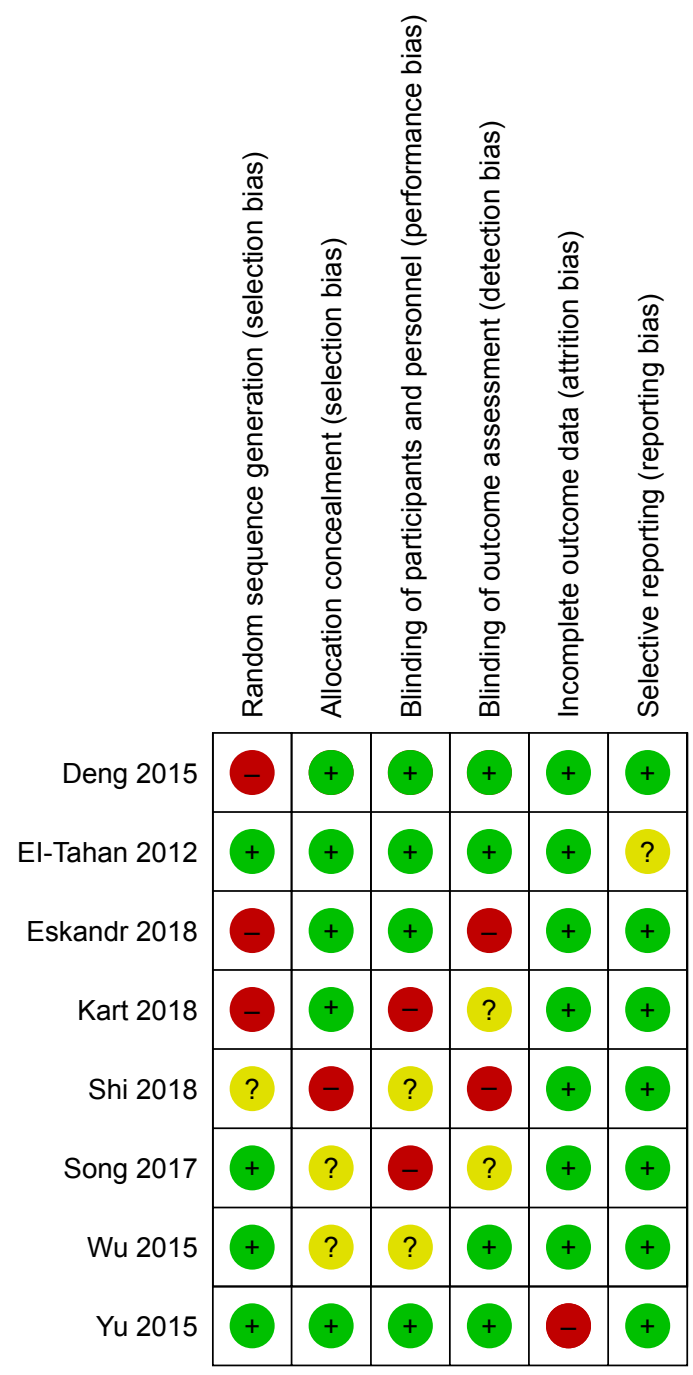

Figure 3 Risk of bias summary.

Notes: “+”, low risk; “-”, high risk; "?”, unclear risk.
Statistical heterogeneity existed in both MAP (79\%) and HR $(90 \%)$. The random effects model was applied. The results showed that the levels of MAP (WMD: -12.83 , 95\% CI $-20.53,-5.14, P=0.001$ ) and HR (WMD: -22.32 , $95 \% \mathrm{CI}-34.55,-10.10, P=0.0003)$ in the dexmedetomidine group were also lower than that in control group. Five RCTs ${ }^{12,13,20-22}$ analyzed the levels of delivery MAP and HR. Obvious heterogeneity was detected in both MAP $\left(I^{2}=63 \%\right)$ and HR $\left(I^{2}=84 \%\right)$. The random effects model was performed for the meta-analysis. The results revealed that the delivery MAP (WMD: $-11.65,95 \%$ $\mathrm{CI}-17.18,-6.13, P<0.0001)$ and HR (WMD: $-19.07,95 \%$ CI $-22.09,-16.04, P<0.00001)$ were also lower than that in control group. Maternal outcomes were shown in Figure 4.

Four studies ${ }^{10,13,21,22}$ assessed the effectiveness of dexmedetomidine on the prevention of postoperative nausea and vomiting (PONV). Although two trials ${ }^{13,22}$ suggested there was no difference in the incidence of nausea or vomiting between dexmedetomidine and placebo. Researchers found that the dexmedetomidine group had a significantly lower incidence of nausea and vomiting than that in the control group, which reported nausea and vomiting for the first postoperative hour. ${ }^{10,21}$ As shown in the study by Wu et al, ${ }^{22}$ dexmedetomidine was significantly more effective than the placebo for the prevention of perioperative shivering $(P<0.05)$.

Furthermore, studies demonstrated that the complications, such as maternal bradyarrhythmia and hypotension, were not reported during cesarean section. ${ }^{1,5}$ Likewise, in the trail of Eskandr et al, ${ }^{11}$ no patients required ephedrine but four required atropine (three in dexmedetomidine group, one in control group); however, these differences were not statistically significant. However, $\mathrm{Yu}$ et $\mathrm{al}^{13}$ described one patient in the dexmedetomidine group and two patients in the control group were treated with ephedrine.

\section{Neonatal outcome}

Five trials ${ }^{10,13,21-23}$ measured umbilical venous blood gas parameters $\left(\mathrm{pH}, \mathrm{pO}_{2}\right.$, and $\left.\mathrm{pCO}_{2}\right)$ at delivery. No significant differences existed between $\mathrm{pH}$ values (WMD: -0.00 , 95\% CI -003, 0.02, $P=0.83$ ), $\mathrm{pO}_{2}$ (WMD: $-0.20,95 \%$ $\mathrm{CI}-1.04,0.64, P=0.64)$ and $\mathrm{pCO}_{2}$ (WMD: $-0.10,95 \%$ $\mathrm{CI}-1.91,1.72, P=0.92$ ) in both groups (Figure 5). Statistical heterogeneity was found both in $\mathrm{pH}\left(I^{2}=61 \%\right)$ and in $\mathrm{pCO}_{2}$ $\left(I^{2}=72 \%\right)$, but not in $\mathrm{pO}_{2}\left(I^{2}=14 \%\right)$. Five studies ${ }^{2,9,10,19,23}$ assessed Apgar scores at 1 and 5 minutes after delivery. No statistical heterogeneity was existed among groups $\left(I^{2}=0 \%\right)$. Therefore, the random effects model was performed for the meta-analysis. There were no differences 
between groups in Apgar scores at 1 minute after delivery (WMD: $-0.12,95 \%$ CI $-0.37,0.12, P=0.33$ ). Statistical heterogeneity was existed among groups $\left(I^{2}=56 \%\right)$ when comparing the Apgar scores at 5 minutes after delivery and the fixed effects model was performed. The results suggested the Apgar scores at 5 minutes after delivery (WMD: $-0.17,95 \% \mathrm{CI}-0.13,0.46, P=0.27$ ) were similar among groups (Figure 6).

A

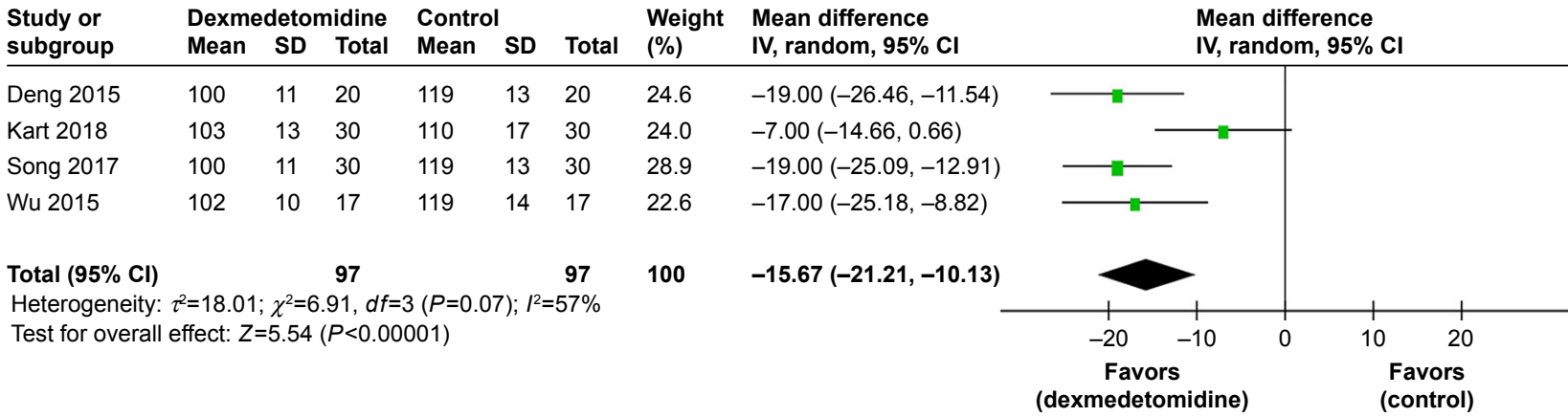

B

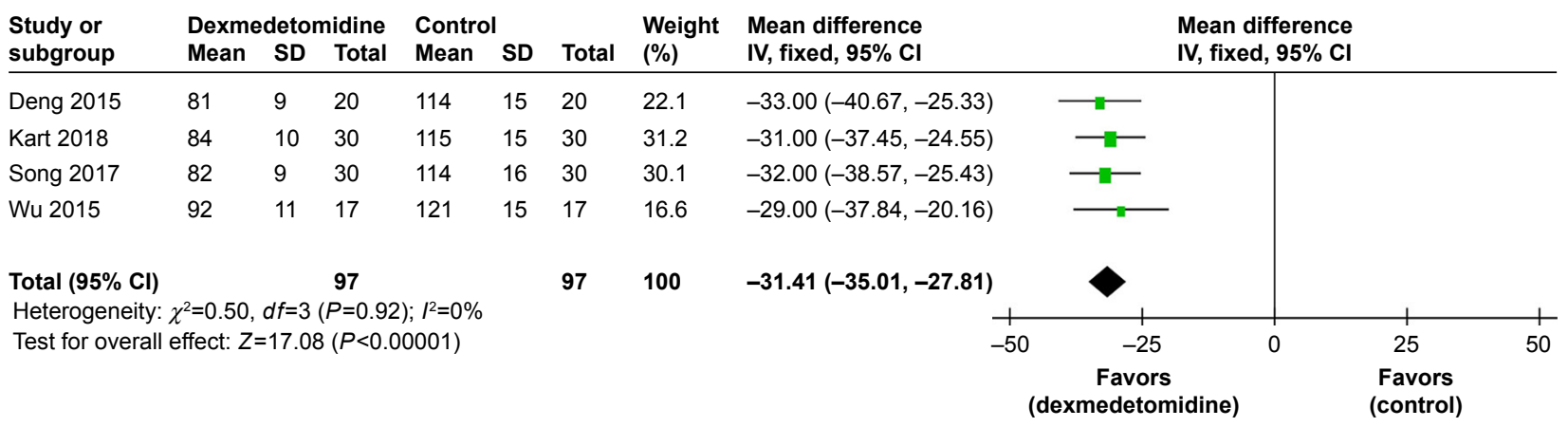

C

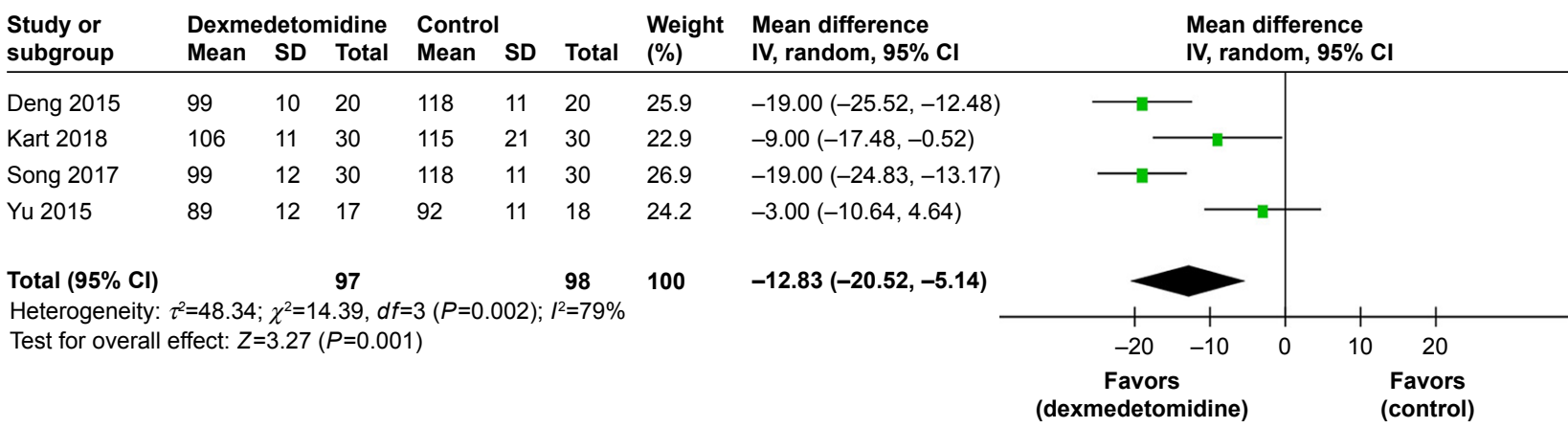

D

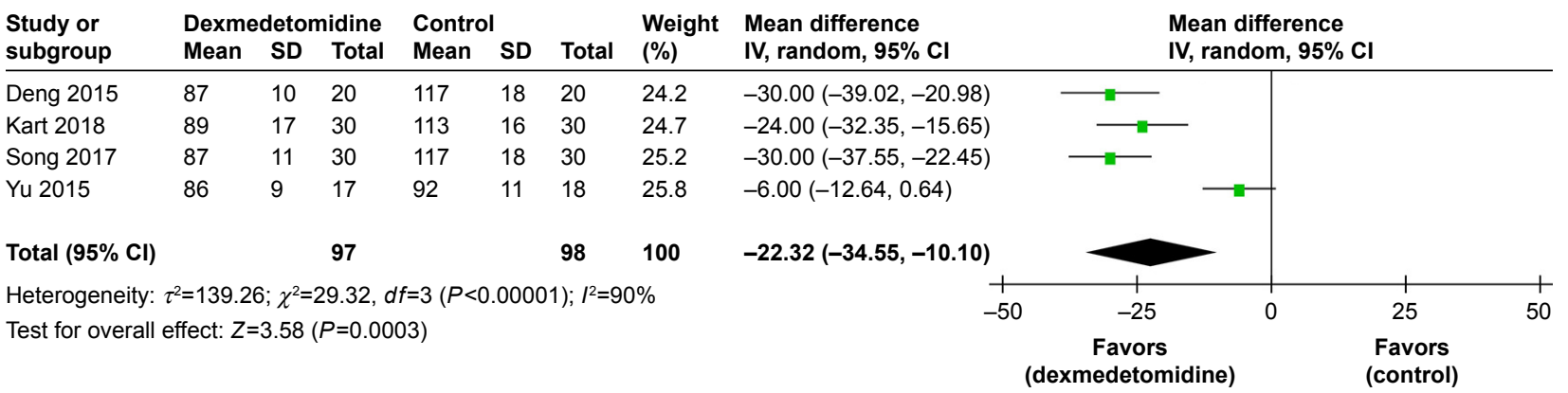

Figure 4 (Continued) 


\section{E}

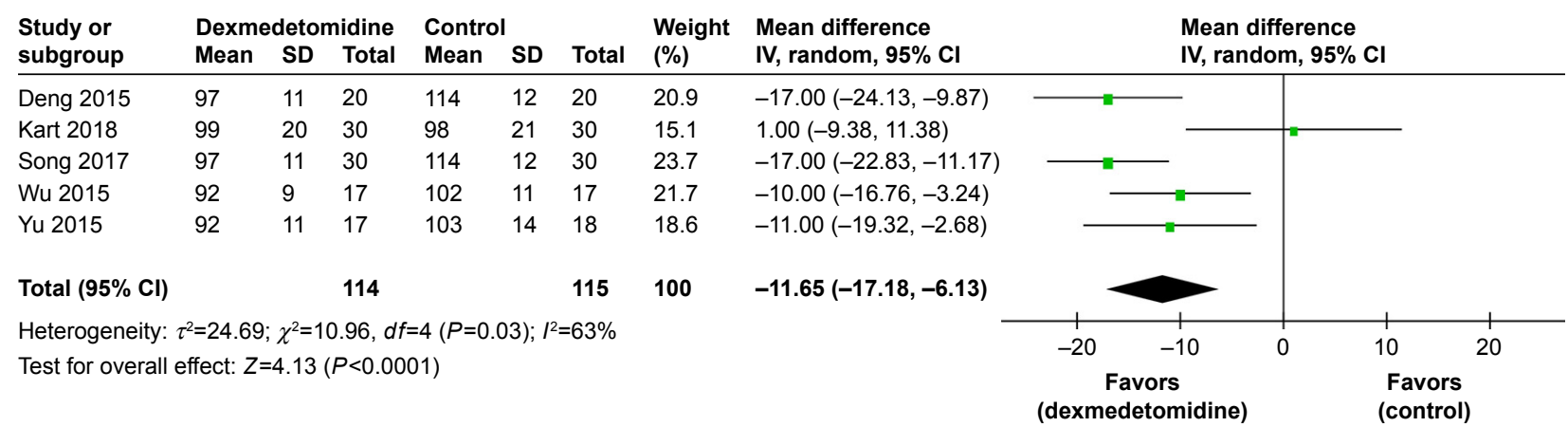

$\mathbf{F}$

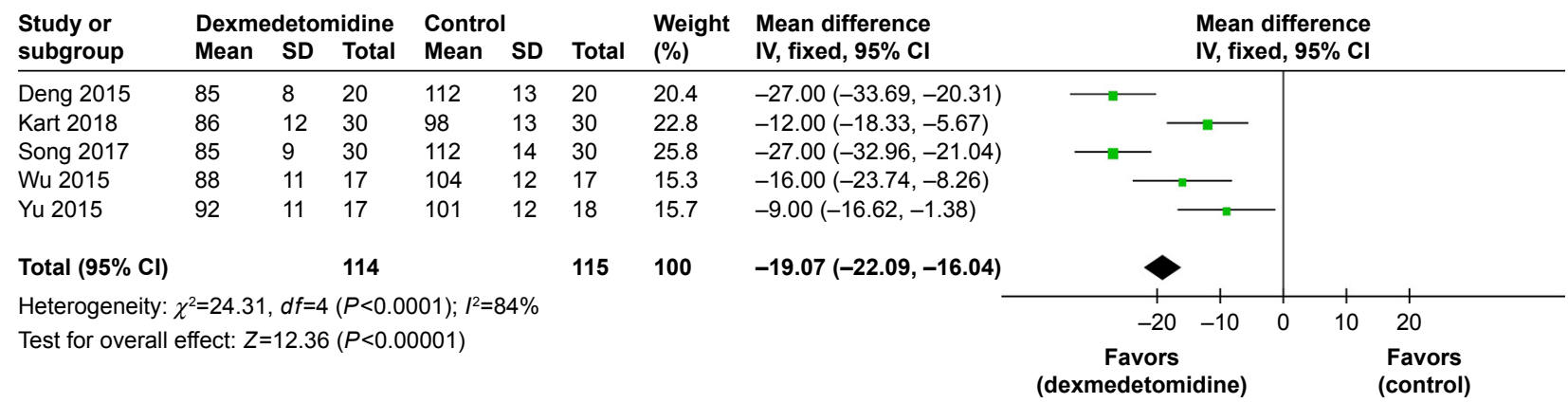

Figure 4 Maternal outcome parameters. (A) MAP at the time of intubation; (B) HR at the time of intubation; (C) MAP at the time of skin incision; (D) HR at the time of skin incision; (E) MAP at the time of delivery; (F) HR at the time of delivery.

Abbreviations: MAP, mean arterial pressure; HR, heart rate.

\section{Discussion}

Cesarean section is a common surgical method and has gained popularity in daily clinical practices. ${ }^{11}$ In addition, surgery without sufficient anesthetics could increase the risk of intra-operative awareness ${ }^{24}$ and cardiovascular responses. However, excessive administration of anesthetics may result in fetal asphyxia, ${ }^{2-4}$ as well as hemodynamic depression of the mother.

As a highly selective alpha-2-adrenergic receptor, dexmedetomidine could reduce the release of norepinephrine via stimulating the alpha-2-adrenergic receptor on the presynaptic membrane and block the transmission of pain signals. This effect could also inhibit the sympathetic nerves' activity, leading to lower hemodynamic response, as well as the effects of sedation and anti-anxiety. Recent evidence showed that cardiovascular responses to endotracheal intubation and surgical procedures may be modulated by dexmedetomidine. ${ }^{24-27}$ Dexmedetomidine has been shown to effectively reduce the requirements of perioperative anesthetics. ${ }^{26-28}$ Furthermore, dexmedetomidine blunted hemodynamic fluctuation and improved the recovery quality. ${ }^{29}$ The results of our meta-analysis were consistent with these previous observations, indicating that the administration of dexmedetomidine could significantly maintain the maternal hemodynamic stability by decreasing stress response during cesarean section. Unfortunately, dexmedetomidine could cause bradycardia in clinical trial by inhibiting sympathetic activity, especially in patient with increased vagal tone or history of atrioventricular block. Only three included studies ${ }^{10,11,21}$ have recorded the incidence of bradycardia, it appears that the incidence in the dexmedetomidine group was higher than that in control group, but no statistical significance was observed. Bradycardia was always transient and reversible; however, it was also worthy of timely attention for leading to serious adverse consequences.

A PRISMA-compliant meta-analysis indicated that dexmedetomidine, regardless of administration modes, was associated with lower incidence of PONV. ${ }^{30}$ The antiemetic effect could be related to the inhibited catecholamine though enhanced parasympathetic tone, as well as to decreased perioperative opioid consumption. Only one included study $^{22}$ demonstrated the occurrence of perioperative shivering in patients undergoing cesarean section. Thus, more studies are still needed to justify whether the application of dexmedetomidine could reduce the incidence of shivering. 
A

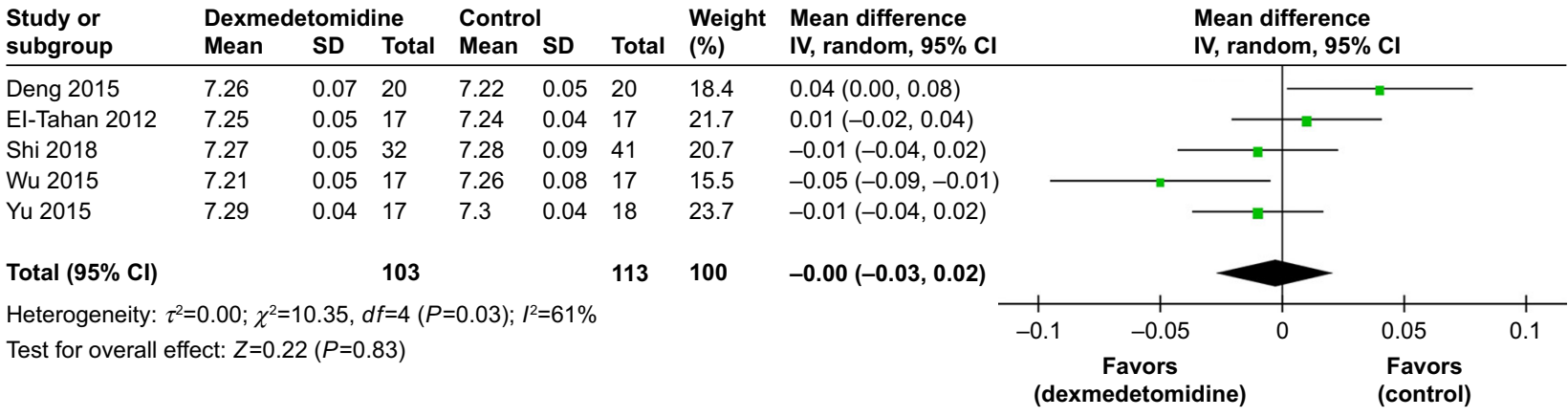

B

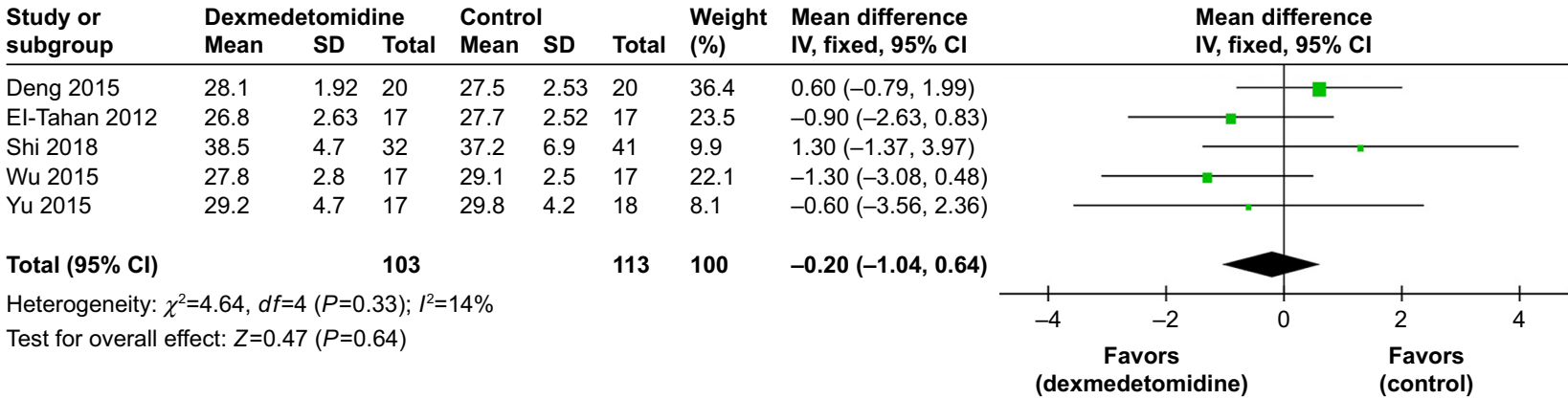

C

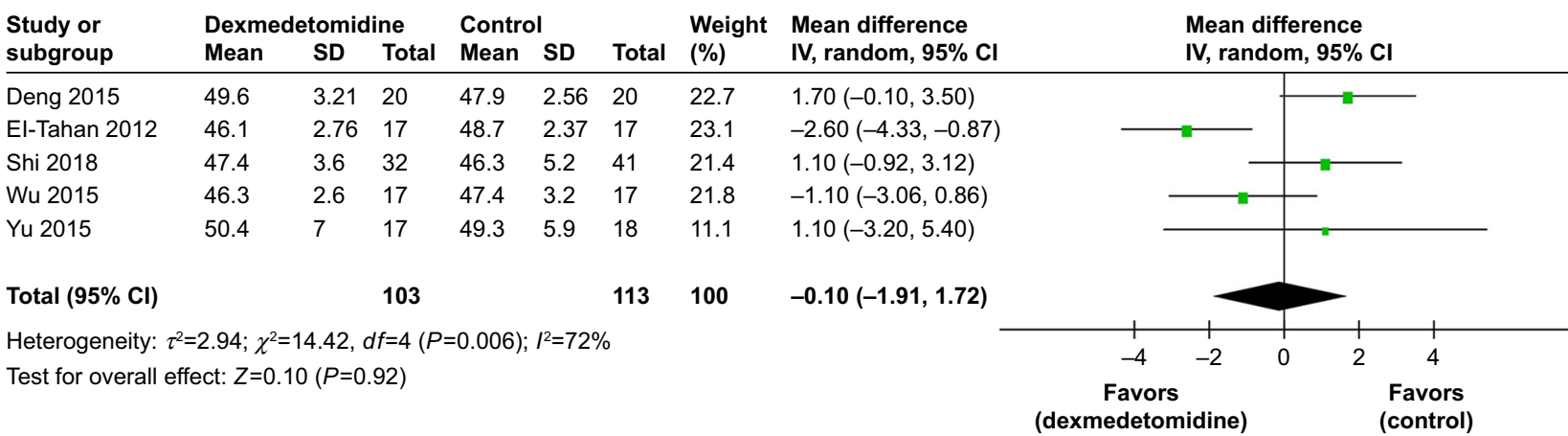

Figure 5 Neonatal outcome: Umbilical blood gas parameters. $(\mathbf{A}) \mathrm{pH}$ of umbilical blood gas; $(\mathbf{B}) \mathrm{pO}_{2}$ of umbilical blood gas; $(\mathbf{C})$ pCO $\mathrm{Cf}_{2}$ umbilical blood gas.

By far, multicenter clinical research about the intravenous application of dexmedetomidine for cesarean delivery under general anesthesia is still lacking. A clinical trial suggested that infusion of dexmedetomidine could not affect the fetus' safety. ${ }^{14}$ The secondary results of our analysis indicated no significant difference in umbilical blood gas parameters and Apgar scores at 1 and 5 minutes among two groups. Although dexmedetomidine could reach the fetus directly through the placenta, significant respiratory depression and sedation in the fetus were not apparent. ${ }^{13,14,31}$ In addition, the fat-soluble properties of dexmedetomidine result in high retention of dexmedetomidine in the placenta, thus reducing the dosage of dexamethasone transferred to the fetus. ${ }^{23}$ The presynaptic alpha-2-adrenergic receptor of the nucleus ceruleus in the brain accounted 'conscious sedation' effect of dexmedetomidine. Different from other sedative drugs, such as midazolam and propofol, which acts on the brain cortex to produce unnatural sedation effects; dexmedetomidine produced a sedative hypnosis effect through acting on the subcortical system. Since the function of the wake-up system is still retained, this sedative hypnosis effect is similar to the state of natural sleep that can be eliminated by verbal or physiological stimulation. Due to this special 'conscious sedation' effect, newborns are naturally able to be 'woken up' and cry by physiological stimuli after delivery.

A meta-analysis of randomized trials about the application of intravenous administration of dexmedetomidine for obstetric anesthesia have emphasized its safety under spinal anesthesia ${ }^{15}$ and the effect on fetal outcomes. ${ }^{32}$ We conducted 
A

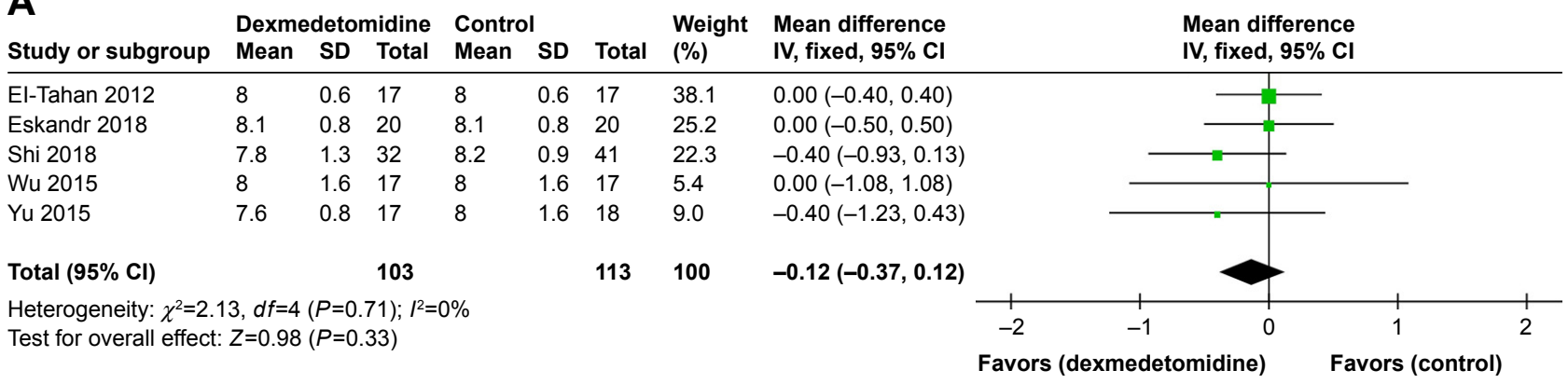

B

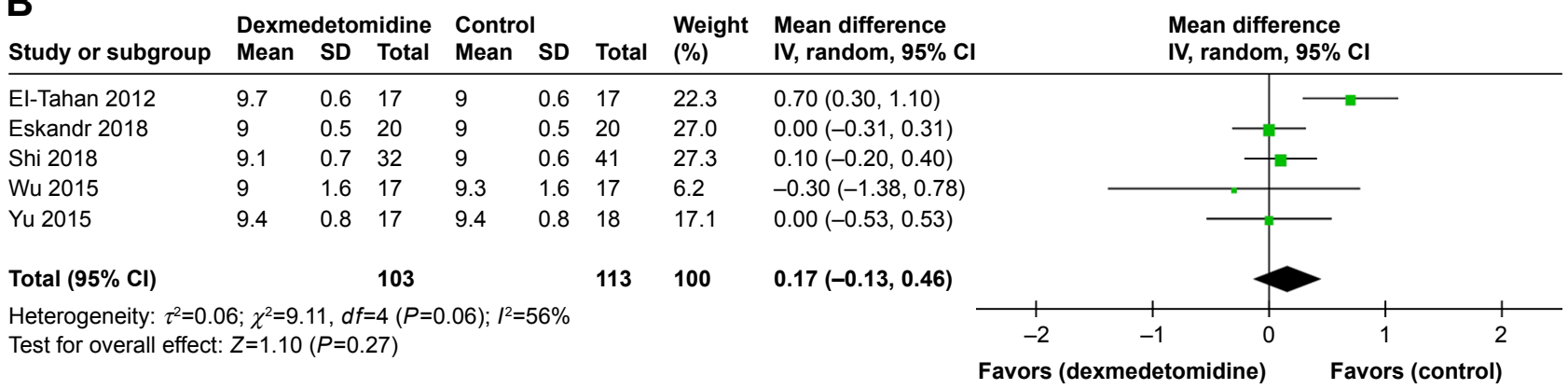

Figure 6 Neonatal outcome: Apgar scores. (A) Apgar scores at I minute after delivery; (B) Apgar scores at 5 minutes after delivery.

this meta-analysis mainly to evaluate the efficacy and safety of intravenous application of dexmedetomidine during cesarean section under general anesthesia. The present study suggested that intravenous administration of dexmedetomidine could efficiently attenuate the maternal cardiovascular response during cesarean section, without affecting the Apgar score of the neonate.

\section{Limitations}

However, there were still several limitations in our study. Firstly, the study had small sample size, as only eight studies were involved in this meta-analysis, which could affect the reliability of this study. Additionally, the strategy of study design, such as dosage and administration modes of dexmedetomidine and other combined anesthetics, could also lead to substantial heterogeneity across the studies. Furthermore, we have not assessed its effects on uterine contraction, intraoperative awareness, postoperative analgesia and other adverse effects due to lack of certain information. Therefore, further studies with larger sample sizes and multi-indicators are warranted to determine the beneficial effects in this meta-analysis.

\section{Conclusion}

In summary, the results of our study suggested that intravenous application of dexmedetomidine could efficiently attenuate maternal cardiovascular response during cesarean section, without affecting the Apgar score of the neonate.

\section{Acknowledgments}

This work was financially supported by grants from the Tangshan Science and Technology Innovation Team Project (18130220A). The authors also thank Professor Jian Zhang for the English language editing.

\section{Disclosure}

The authors report no conflicts of interest in this work.

\section{References}

1. Huang CJ, Fan YC, Tsai PS. Differential impacts of modes of anaesthesia on the risk of stroke among preeclamptic women who undergo caesarean delivery: a population-based study. Br J Anaesth. 2010;105(6):818-826.

2. Maghsoudloo M, Eftekhar N, Ashraf MA, Khan ZH, Sereshkeh HP. Does intravenous fentanyl affect Apgar scores and umbilical vessel blood gas parameters in cesarean section under general anesthesia? Acta Med Iran 2011;49(8):517-522.

3. Mattingly JE, D'Alessio J, Ramanathan J. Effects of obstetric analgesics and anesthetics on the neonate: a review. Paediatr Drugs. 2003;5(9): 615-627.

4. Draisci G, Valente A, Suppa E, et al. Remifentanil for cesarean section under general anesthesia: effects on maternal stress hormone secretion and neonatal well-being: a randomized trial. Int JObstet Anesth. 2008;17(2):130-136.

5. Mantz J, Josserand J, Hamada S. Dexmedetomidine: new insights. Eur J Anaesthesiol. 2011;28(1):3-6.

6. Hall JE, Uhrich TD, Barney JA, Arain SR, Ebert TJ. Sedative, amnestic, and analgesic properties of small-dose dexmedetomidine infusions. Anesth Analg. 2000;90(3):699-705.

7. Zeng X, Jiang J, Yang L, Ding W. Epidural dexmedetomidine reduces the requirement of propofol during total intravenous anaesthesia and improves analgesia after surgery in patients undergoing open thoracic surgery. Sci Rep. 2017;7(1):3992.

8. Cortegiani A, Accurso G, Gregoretti C. Should we use dexmedetomidine for sedation in parturients undergoing caesarean section under spinal anaesthesia? Turk J Anaesth Reanim. 2017;45(5):249-250. 
9. Wang J, Han Z, Zhou H, Wang N, Ma H. Effective loading dose of dexmedetomidine to induce adequate sedation in parturients undergoing caesarean section under spinal anaesthesia. Turk $J$ Anaesth Reanim. 2017;45(5):260-263.

10. El-Tahan MR, Mowafi HA, Al Sheikh IH, Khidr AM, Al-Juhaiman RA. Efficacy of dexmedetomidine in suppressing cardiovascular and hormonal responses to general anaesthesia for caesarean delivery: a dose-response study. Int J Obstet Anesth. 2012;21(3):222-229.

11. Eskandr AM, Metwally AA, Ahmed AA, et al. Dexmedetomidine as a part of general anaesthesia for caesarean delivery in patients with pre-eclampsia: a randomised double-blinded trial. Eur J Anaesthesiol. 2018;35(5):372-378.

12. Kart K, Hanci A. Effects of remifentanil and dexmedetomidine on the mother's awareness and neonatal Apgar scores in caesarean section under general anaesthesia. J Int Med Res. 2018;46(5):1846-1854.

13. Yu M, Han C, Jiang X, et al. Effect and placental transfer of dexmedetomidine during caesarean section under general anaesthesia. Basic Clin Pharmacol Toxicol. 2015;117(3):204-208.

14. Li C, Li Y, Wang K, Kong X. Comparative evaluation of remifentanil and dexmedetomidine in general anesthesia for cesarean delivery. Med Sci Monit. 2015;21:3806-3813.

15. Bao Z, Zhou C, Wang X, Zhu Y. Intravenous dexmedetomidine during spinal anaesthesia for caesarean section: a meta-analysis of randomized trials. J Int Med Res. 2017;45(3):924-932.

16. Higgins JP, Altman DG, Gøtzsche PC, et al. The Cochrane Collaboration's tool for assessing risk of bias in randomised trials. $B M J$. 2011;343:d5928.

17. The Nordic Cochrane Centre TCC. Review Manager (Rev Man). Version 5.3. Copenhagen: The Nordic Cochrane Centre, The Cochrane Collaboration; 2014.

18. Luo D, Wan X, Liu J, Tong T. Optimally estimating the sample Mean from the sample size, median, mid-range, and/or mid-quartile range. Stat Methods Med Res. 2018;27(6):1785-1805.

19. Wan X, Wang W, Liu J, Tong T. Estimating the sample mean and standard deviation from the sample size, median, range and/or interquartile range. BMC Med Res Methodol. 2014;14(1):135.

20. Song Q, Song HX, Bian HC, Gao CJ. Effects of preoperative infusion of dexmedetomidine on stress response and hemodynamics of patients undergoing cesarean section under general anesthesia. Chin J Woman Child Health Res. 2017;28(9):1154-1156. Chinese.

21. Deng $\mathrm{C}, \mathrm{Wu} \mathrm{W}$. Effect of dexmedetomidine in suppressing cardiovascular and hormonal responses to general anaesthesia for caesarean delivery. Sichuan Med J. 2015;36(2):191-194. Chinese.
22. Wu X, Yuan DX, Han CB, et al. Efficacy of dexmedetomidine in cesarean section under general anesthesia. Jiangsu Med J. 2015;41(20): 2397-2400. Chinese.

23. Shi W, Huang BW, Luo YW, et al. Effect of dexmedetomidine on endotracheal intubation response during general anesthesia in pregnant women undergoing cesarean section. J Guangdong Med Univ. 2018; 36(1):100-103. Chinese.

24. Pandit JJ, Andrade J, Bogod DG, et al. 5th National Audit Project (NAP5) on accidental awareness during general anaesthesia: summary of main findings and risk factors. Br J Anaesth. 2014;113(4):549-559.

25. Gaszyński T, Czarnik K, Laziński L, et al. Dexmedetomidine for attenuating haemodynamic response to intubation stimuli in morbidly obese patients anaesthetised using low-opioid technique: comparison with fentanyl-based general anaesthesia. Anaesthesiol Intensive Ther. 2016;48(5):275-279.

26. El-Shmaa NS, El-Baradey GF. The efficacy of labetalol vs dexmedetomidine for attenuation of hemodynamic stress response to laryngoscopy and endotracheal intubation. J Clin Anesth. 2016;31:267-273.

27. Kumari K, Gombar S, Kapoor D, Sandhu HS. Clinical study to evaluate the role of preoperative dexmedetomidine in attenuation of hemodynamic response to direct laryngoscopy and tracheal intubation. Acta Anaesthesiol Taiwan. 2015;53(4):123-130.

28. Schnabel A, Meyer-Frießem CH, Reichl SU,Zahn PK, Pogatzki-ZahnEM. Is intraoperative dexmedetomidine a new option for postoperative pain treatment? A meta-analysis of randomized controlled trials. Pain. 2013;154(7):1140-1149.

29. Rani P, Hemanth Kumar VR, Ravishankar M, et al. Rapid and reliable smooth extubation - comparison of fentanyl with dexmedetomidine: a randomized, double-blind clinical trial. Anesth Essays Res. 2016;10(3):597-601.

30. Jin S, Liang DD, Chen C, Zhang M, Wang J. Dexmedetomidine prevent postoperative nausea and vomiting on patients during general anesthesia: a PRISMA-compliant meta analysis of randomized controlled trials. Medicine. 2017;96(1):e5770.

31. Bilotta F, Rosa G. 'Anesthesia' for awake neurosurgery. Curr Opin Anaesthesiol. 2009;22(5):560-565.

32. Zhang J, Zhou H, Sheng K, Tian T, Wu A. Foetal responses to dexmedetomidine in parturients undergoing caesarean section: a systematic review and meta-analysis. J Int Med Res. 2017;45(5):1613-1625.
Drug Design, Development and Therapy

\section{Publish your work in this journal}

Drug Design, Development and Therapy is an international, peerreviewed open-access journal that spans the spectrum of drug design and development through to clinical applications. Clinical outcomes, patient safety, and programs for the development and effective, safe, and sustained use of medicines are the features of the journal, which

\section{Dovepress}

has also been accepted for indexing on PubMed Central. The manuscript management system is completely online and includes a very quick and fair peer-review system, which is all easy to use. Visit http://www.dovepress.com/testimonials.php to read real quotes from published authors. 